\title{
A new understanding of the effect of filler minerals on the precipitation of synthetic C-S-H
}

\author{
Zengqi Zhang ${ }^{1}$, Qiang Wang ${ }^{1 *}$, Mingzhong Zhang $^{2}$, Zongxian Huang ${ }^{1}$, Shiyu Zhuang ${ }^{1}$ \\ ${ }^{1}$ Department of Civil Engineering, Tsinghua University, Beijing 100084, China \\ ${ }^{2}$ Department of Civil, Environmental and Geomatic Engineering, University College London, \\ London WC1E 6BT, UK
}

*Corresponding author. E-mail address: w-qiang@tsinghua.edu.cn (Qiang Wang)

\begin{abstract}
The filler effect is the most important physical mechanism of mineral admixtures in the early hydration of cement whose chemical properties greatly affect the precipitation of C-S-H. In this study, calcite, strontianite, magnesite, dolomite, quartz, whewellite and whitlockite were selected as the fillers. The morphology and reaction kinetics of synthetic C-S-H precipitated on the surfaces of different fillers were studied via electron microscopy observations and electrical conductivity and ion concentration measurements. The precipitation rate of $\mathrm{C}-\mathrm{S}-\mathrm{H}$ has a positive correlation with the affinity of $\mathrm{Ca}^{2+}$ for adsorption on the fillers, which can be explained by the nucleation barrier of $\mathrm{C}$ S-H. Extremely ordered honeycomb-like morphology of the C-S-H is found on calcite and strontianite surfaces, while less regular leaf-like or honeycomb-like C-S-H are found on whewellite and whitlockite. The ordered C-S-H pattern is related to the lattice cleavage of the ionic compound filler. In the case of quartz, C-S-H prefers growth along the tangential direction, which is quite different from the normal-direction growth on ionic compounds. The in-plane growth of C-S-H on quartz is believed to be induced by a layer of loosely physically-adsorbed $\mathrm{Ca}^{2+}$.
\end{abstract}

Key words: filler; synthetic C-S-H; morphology; microstructure; kinetics

\section{Introduction}

Fine-grained limestone and quartz powders have been used as fillers (i.e., not the coarse-grained aggregates) in the preparation of concretes by partially replacing Portland cement [1-3]. These fillers are commonly recognized as inert materials in cementitious material systems [3-6]. The main positive effect of these added fillers on the hydration of cement is that they accelerate the nucleation of the hydration product (calcium silicate hydrate, $\mathrm{C}-\mathrm{S}-\mathrm{H}$ ) by providing more nucleation sites on the surface $[7,8]$. Such a nucleation effect of the fillers is quite important to the properties of cementitious materials during the early stage when the C-S-H is rapidly precipitating and the microstructure is rapidly developing. 
The affinity of fillers for C-S-H is related to the chemical properties of their surfaces. French et al. [9], Bentz et al. [10], Mehta et al. [11] and Ouyang et al. [12] found that the bond strength between $\mathrm{C}-\mathrm{S}-\mathrm{H}$ and calcite is much stronger than that between $\mathrm{C}-\mathrm{S}-\mathrm{H}$ and silica. They proposed that this phenomenon is caused by the different interactions between the fillers and $\mathrm{Ca}^{2+}$ : strong acid-base interactions between calcite and $\mathrm{Ca}^{2+}$ and a relatively weak electrostatic force between silica and $\mathrm{Ca}^{2+}$. Oey et al. [13] and Kumar et al. [14] also found that the accelerated effect of calcite on the Portland cement hydration is stronger than that of quartz. They proposed that the ion-exchange reactions between $\mathrm{CO}_{3}{ }^{2-}$ (from calcite) and $\mathrm{OH}^{-}$(from C-S-H) make limestone a superior filler to quartz. In addition to the precipitation kinetics, the morphology of C-S-H is also significantly affected by the chemical properties of filler surfaces. An ordered pattern of the precipitated C-S-H was observed on the surface of calcite by Sato et al. [15], Bentz et al. [10], Ouyang et al. [8] and Berodier et al. [7], which is also attributed to the strong chemical bonding of $\mathrm{Ca}^{2+}$ to the calcite surface. In the above investigations, only the differences in the filler effects between calcite and quartz were studied. Other types of inert materials should be studied to verify the effects of surface's chemical properties on the affinity of fillers with the C-S-H. Additionally, no direct evidence has been found to prove that the adsorption affinity of $\mathrm{Ca}^{2+}$ with certain fillers leads to different bonding strengths and various morphologies of the C-S-H, although the higher adsorption affinity of $\mathrm{Ca}^{2+}$ on calcite has been observed by zeta-potential tests $[8,12]$.

This paper reports the morphology and precipitation kinetics of the synthetic C-S-H formed on the surfaces of various inert fillers. The properties of the synthetic C-S-H have been investigated in prior studies [16-25]. By selecting the synthetic C-S-H as the studied target, other undesired interferences from many factors can be eliminated, such as the reaction of the aluminate phases in Portland cement and the dissolution process of alite. In this study, seven different inert fillers with different adsorption capacities for calcium ions were selected as the substrates for the growth of synthetic C-S-H. Studying different types of inert fillers is helpful to verify the dominant mechanism of the filler effect.

\section{Experimental}

\subsection{Raw materials}

The as-received calcium nitrate tetrahydrate $\left(\mathrm{Ca}\left(\mathrm{NO}_{3}\right)_{2} \cdot 4 \mathrm{H}_{2} \mathrm{O}\right)$, sodium silicate $\left(\mathrm{Na}_{2} \mathrm{SiO}_{3} \cdot 9 \mathrm{H}_{2} \mathrm{O}\right)$ 
and sodium hydroxide $(\mathrm{NaOH})$ produced by Aladdin Reagent Co. Ltd. were used for the synthesis of C-S-H. The fillers were calcite $\left(\mathrm{CaCO}_{3}\right)$, strontianite $\left(\mathrm{SrCO}_{3}\right)$, magnesite $\left(\mathrm{MgCO}_{3}\right)$, dolomite $\left(\mathrm{MgCa}\left(\mathrm{CO}_{3}\right)_{2}\right)$, quartz $\left(\mathrm{SiO}_{2}\right)$, whewellite $\left(\mathrm{CaC}_{2} \mathrm{O}_{4}\right)$ and whitlockite $\left(\mathrm{Ca}_{3}\left(\mathrm{PO}_{4}\right)_{2}\right)$. All of the fillers are fine powders and the specific surface areas $(S S A s)$ of these fillers were determined from nitrogen adsorption isotherms using the BET equations, which are presented in Table 1. The crystal systems and solubility product constant $\left(K_{s p}\right)$ of these fillers are also given in Table 1.

Table 1 Physical and chemical properties of the selected fillers

\begin{tabular}{ccccc}
\hline Filler & Chemical formula & Crystal system & $\log K_{s p}$ & $S S A\left(\mathrm{~m}^{2} / \mathrm{kg}\right)$ \\
\hline Calcite & $\mathrm{CaCO}_{3}$ & trigonal & $-8.48^{\mathrm{a}}$ & 926.7 \\
Strontianite & $\mathrm{SrCO}_{3}$ & orthorhombic & $-9.27^{\mathrm{a}}$ & 1682.3 \\
Magnesite & $\mathrm{MgCO}_{3}$ & trigonal & $-8.10^{\mathrm{b}}$ & 2359.2 \\
Dolomite & $\mathrm{MgCa}^{\mathrm{b}}\left(\mathrm{CO}_{3}\right)_{2}$ & trigonal & $-17.12^{\mathrm{b}}$ & 2351.1 \\
Quartz & $\mathrm{SiO}_{2}$ & trigonal & $-4.01^{\mathrm{a}}$ & 935.2 \\
Whewellite & $\mathrm{CaC}_{2} \mathrm{O}_{4}$ & monoclinic & $-8.69^{\mathrm{c}}$ & 4577.5 \\
Whitlockite & $\mathrm{Ca}_{3}\left(\mathrm{PO}_{4}\right)_{2}$ & trigonal & $-28.92^{\mathrm{a}}$ & 910.1 \\
\hline
\end{tabular}

Note: $a$ from minteq.v4.dat and $b$ from ThermoChimie_PHREEQC_eDH_v9b0.dat, databases of the thermodynamic program PHREEQC [26]; $c$ from Burgos-Cara [27].

\subsection{Synthesis of $C-S-H$}

First, Solution A was prepared by dissolving $3 \mathrm{mmol} \mathrm{Ca}\left(\mathrm{NO}_{3}\right)_{2} \cdot 4 \mathrm{H}_{2} \mathrm{O}$ in $30 \mathrm{ml}$ deionized $(D I)$ water, and Solution B was prepared by dissolving $3 \mathrm{mmol} \mathrm{Na} \mathrm{SiO}_{3} \cdot 9 \mathrm{H}_{2} \mathrm{O}$ in $30 \mathrm{ml} \mathrm{DI}$ water. Second, Solution $\mathrm{C}$ was prepared by dissolving $0.16 \mathrm{~g} \mathrm{NaOH}(4 \mathrm{mmol})$ in $40 \mathrm{ml} \mathrm{DI}$ water and was used to maintain the alkalinity of the solutions during the synthesis process. Then, the C-S-H was synthesized according to the specific synthetic procedure, which is summarized schematically in Fig. 1. It should be noted that the total surface areas of different fillers added into solution $C$ were all $6 \mathrm{~m}^{2}$. This is the most appropriate mix proportion: both increasing and decreasing the total surface areas would change the distribution density of the $\mathrm{CSH}$ on the filler surfaces, which is not suitable for the observation of microstructure under SEM and TEM. The synthetic procedure of the pure CSH is similar to that presented in Fig. 1, but no fillers were added in Solution C. 


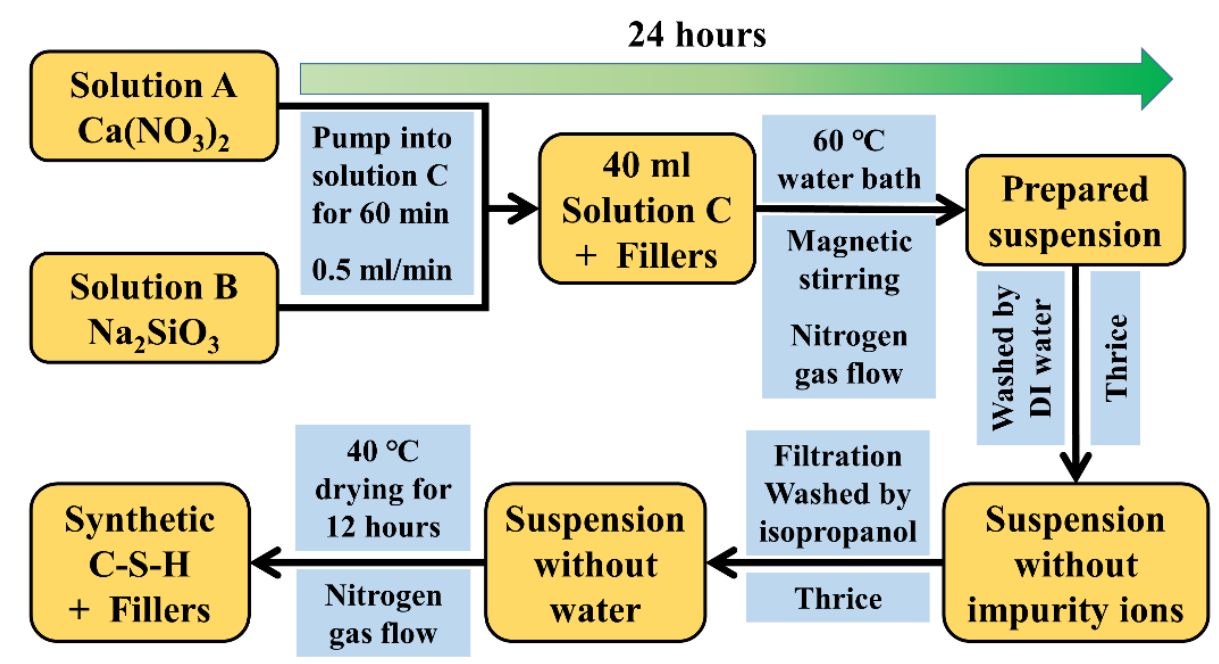

Fig. 1 Schematic diagram of the synthetic procedure of C-S-H with fillers.

XRD analysis was used to characterize the crystalline structure of synthetic C-S-H without fillers, and the result is presented in Fig. 2. The XRD pattern of synthetic C-S-H exhibits tobermorite-like reflections, which is consistent with those previously reported by Popova [28] and Plank [19]. The XRD pattern of the ordinary Portland cement (OPC) paste is also provided in Fig. 2 and it was found that the CSH produced in OPC paste mainly presented as amorphous bulge.

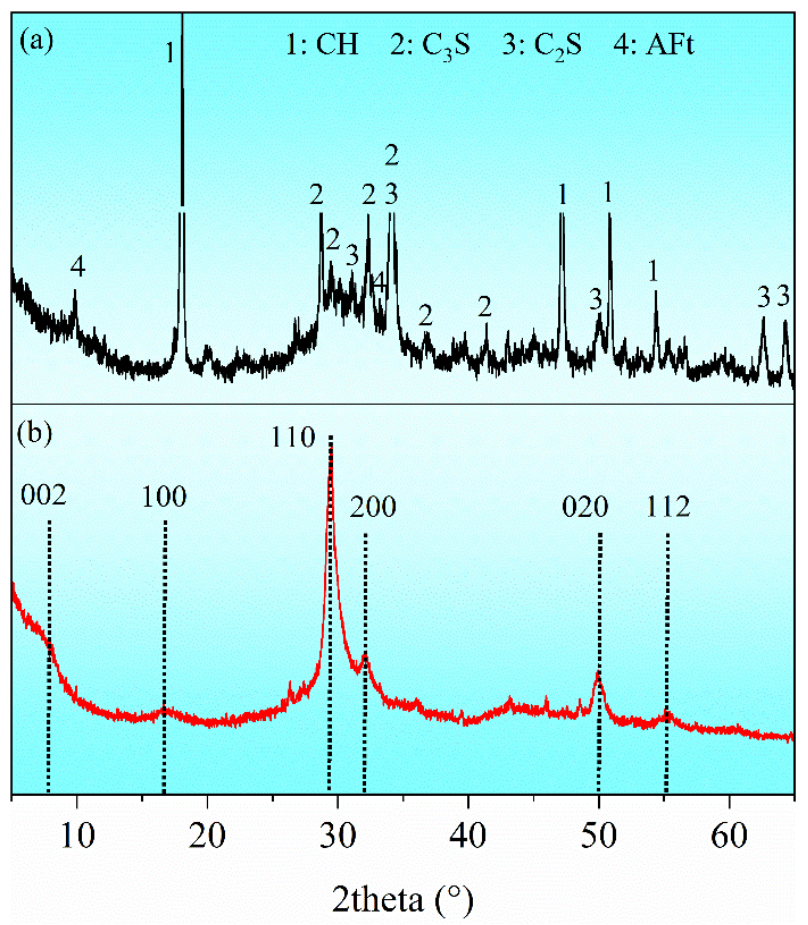

Fig. 2 XRD patterns. (a) OPC paste at 360 days; (b) synthetic C-S-H without fillers.

\subsection{Morphology and structure observation}

\subsubsection{SEM imaging}


A Quanta 200 FEG environmental scanning electron microscope (ESEM, FEI) was used for morphological and microstructural observations of synthetic C-S-H. Synthetic C-S-H with or without fillers was dispersed separately on the sample stage and treated with carbon plating. The SEM observation was conducted at an accelerating voltage of $10 \mathrm{keV}$.

\subsubsection{TEM imaging}

Transmission electron microscope (TEM, JEM-2010F) equipped with the additional feature of energy-dispersive X-ray spectroscopy (EDS) was used for the microstructural observation of the synthetic C-S-H. Approximately $1.0 \mathrm{~g}$ synthetic C-S-H with or without fillers were diluted in $100 \mathrm{ml}$ ethanol and further dispersed in an ultrasonic bath for $15 \mathrm{~min}$. The well-dispersed dispersions were dropped on a \#400 Cu mesh with carbon support films. Then, synthetic C-S-H was observed by TEM, and the elemental composition was collected by the EDS.

\subsection{Precipitation kinetics monitoring}

\subsubsection{Electrical conductivity}

To monitor the precipitation kinetics of synthetic C-S-H, the electrical conductivity of the preparation solutions was auto-recorded by a METTLER TOLEDO FE38 conductometer connected to a Personal Computer. Prior to the testing, the electrode was calibrated by $\mathrm{KCl}$ standard solutions with different conductivities of $0.1466,1.408,12.85$ and $111.3 \mathrm{mS} / \mathrm{cm}$. In the conductivity monitoring procedure, $30 \mathrm{ml}$ of both Solutions A and B were pumped into $100 \mathrm{ml} \mathrm{DI}$ water at a rate of $0.5 \mathrm{ml} / \mathrm{min}$ with magnetic stirring. The electrical conductivity of the mixed solution was monitored and recorded continuously.

\subsubsection{Ion concentrations}

In addition to monitoring the electrical conductivity, the ion concentrations of the solutions were also determined to characterize the precipitation kinetics of the synthetic C-S-H. At 1, 3, 6, 9, 12, 15 , $18,30,45,60,100,200,400,800,1400$, and $2500 \mathrm{~min}$, approximately $10 \mathrm{ml}$ of the mixed solution was removed and centrifuged for $5 \mathrm{~min}$ at $10500 \mathrm{rpm}$, and the supernatant liquid was collected and filtered using a syringe filter with filter paper of $0.22 \mu \mathrm{m}$ in the opening size, followed by dilution with $2 w t \% \mathrm{HNO}_{3}$ solution. The concentrations of both $\mathrm{Ca}$ and $\mathrm{Si}$ were determined by an $\mathrm{X}$ Series inductively coupled plasma optical emission spectrometer (ICP-OES, Thermo).

\subsection{Adsorption of $\mathrm{Ca}^{2+}$ on the surfaces of fillers}




\subsubsection{Zeta-potential test}

The surface charge or the zeta-potential of the suspended particles is significantly affected by the adsorption of ions [29]; thus, many papers have presented the adsorption behaviour of ions through the zeta-potential test $[8,12,30,31]$. In this study, the preferential adsorptions of calcium on different fillers were characterized by determining the zeta-potential of the fillers suspended in $\mathrm{Ca}(\mathrm{OH})_{2}$ solutions at various concentrations of from 0.2 to $20 \mathrm{mM}$. The total surface areas of the different fillers were $6 \mathrm{~m}^{2}$ in $30 \mathrm{ml} \mathrm{Ca}(\mathrm{OH})_{2}$. After continuous stirring for 48 hours under the $\mathrm{N}_{2}$ environment, the zeta-potential of the suspensions was determined by a Malvern Zetasizer Nano instrument.

\subsubsection{Measurement of $\mathrm{Ca}^{2+}$ concentration}

The changes in the concentrations of the suspensions directly reflect the adsorption behaviour of $\mathrm{Ca}^{2+}$ on the surface of the fillers. Fillers with total surface areas of $30 \mathrm{~m}^{2}$ were added into $30 \mathrm{ml}$ $\mathrm{Ca}(\mathrm{OH})_{2}$ solutions. After continuous stirring for 48 hours, the suspension was centrifuged for 5 min at $10500 \mathrm{rpm}$, and the supernatant liquid was collected and filtered using a syringe filter $(0.22 \mu \mathrm{m})$, followed by dilution with $2 \% w t \mathrm{HNO}_{3}$. Then, the concentrations of $\mathrm{Ca}$ in the diluted supernatant liquid were measured by ICP-OES. Considering the mineralogical transformation [32], the concentrations of $\mathrm{Mg}$ and $\mathrm{Sr}$ were also determined in the suspensions containing strontianite, magnesite and dolomite.

\section{Results and discussion}

\subsection{Adsorption of $\mathrm{Ca}^{2+}$ on fillers}

\subsubsection{Ion concentrations}

The adsorption of $\mathrm{Ca}^{2+}$ onto the surfaces of fillers in the alkaline $\mathrm{Ca}(\mathrm{OH})_{2}$ solutions with concentrations from 0.2 to $20 \mathrm{mM}$ is presented in Fig. 3. In the aqueous suspensions of calcite, whewellite, whitlockite and quartz, no cation exchange occurrs, and the amount of adsorbed $\mathrm{Ca}^{2+}$ can be considered as the difference between the initial and equilibrated $\mathrm{Ca}^{2+}$ concentrations. As shown in Fig. 3a, the adsorption affinity of $\mathrm{Ca}^{2+}$ on calcite is the largest, while that on quartz is the lowest. This phenomenon is caused by the different adsorption mechanisms of $\mathrm{Ca}^{2+}$ on calcite and quartz, which

have been discussed by Ouyang et al. $[8,12]$. The adsorption of $\mathrm{Ca}^{2+}$ on calcite was reported to be enthalpically driven, and the strong acid-base interaction results in strong adsorption and bonding 
between $\mathrm{Ca}^{2+}$ and calcite [30,31]. Contrary to the situation in calcite systems, the adsorption of $\mathrm{Ca}^{2+}$ on quartz is governed by a relatively weak electrostatic force, which results in high mobility and low content of adsorbed $\mathrm{Ca}^{2+}$ [33-35]. Similar to calcite, whewellite and whitlockite are both ionic compounds. Thus, the adsorption of $\mathrm{Ca}^{2+}$ on whewellite and whitlockite is also expected to be enthalpically driven. In the case of calcite, the adsorption of $\mathrm{Ca}^{2+}$ on calcite is due to the strong acidbase interaction between $\mathrm{Ca}^{2+}$ and $\mathrm{CO}^{3-}$, while in the cases of whewellite and whitlockite, the active surface sites are $\mathrm{C}_{2} \mathrm{O}_{4}{ }^{2-}$ and $\mathrm{PO}_{4}{ }^{3-}$, respectively. As shown in Fig. 3a, the adsorption contents of $\mathrm{Ca}^{2+}$ on whewellite and whitlockite are higher than that on quartz, illustrating the relatively high affinity of $\mathrm{Ca}^{2+}$ for adsorption on ionic compounds with low solubility. However, the affinity of $\mathrm{Ca}^{2+}$ for adsorption on whewellite and whitlockite is slightly less than that on calcite. It is believed that the abilities of ionic compounds to adsorb $\mathrm{Ca}^{2+}$ are related to the strength of the acid-base interaction and the lattice $\mathrm{Ca}^{2+}$ density on the surface of the fillers. Compared to that of whewellite and whitlockite, the lattice $\mathrm{Ca}^{2+}$ density on the surface of calcite is higher due to its smaller lattice volume.

In the cases of strontianite, magnesite and dolomite, cation exchanges between fillers and $\mathrm{Ca}(\mathrm{OH})_{2}$ occur:

$$
\begin{gathered}
\mathrm{SrCO}_{3}+\mathrm{Ca}^{2+}=\mathrm{CaCO}_{3}+\mathrm{Sr}^{2+} \\
\mathrm{MgCO}_{3}+\mathrm{Ca}^{2+}=\mathrm{CaCO}_{3}+\mathrm{Mg}^{2+} \\
\mathrm{MgCa}\left[\mathrm{CO}_{3}\right]_{2}+\mathrm{Ca}^{2+}=2 \mathrm{CaCO}_{3}+\mathrm{Mg}^{2+}
\end{gathered}
$$

In the suspension of strontianite, the ion activity ratio of $\left\{\mathrm{Sr}^{2+}\right\}$ to $\left\{\mathrm{Ca}^{2+}\right\}$ can be calculated according to the chemical equilibrium constant in Table 1.

$$
\begin{gathered}
\left\{\mathrm{Sr}^{2+}\right\} \times\left\{\mathrm{CO}_{3}^{2-}\right\}=10^{-9.27} \\
\left\{\mathrm{Ca}^{2+}\right\} \times\left\{\mathrm{CO}_{3}^{2-}\right\}=10^{-8.48} \\
\left\{\mathrm{Sr}^{2+}\right\} /\left\{\mathrm{Ca}^{2+}\right\}=10^{-9.27} / 10^{-8.48}=0.1622
\end{gathered}
$$

The ion activity ratio of $\left\{\mathrm{Mg}^{2+}\right\}$ to $\left\{\mathrm{Ca}^{2+}\right\}$ in the suspensions of magnesite and dolomite can be determined with the same method:

$$
\begin{gathered}
\left\{\mathrm{Mg}^{2+}\right\} \times\left\{\mathrm{CO}_{3}^{2-}\right\}=10^{-8.1} \\
\left\{\mathrm{Ca}^{2+}\right\} \times\left\{\mathrm{CO}_{3}^{2-}\right\}=10^{-8.48} \\
\left\{\mathrm{Mg}^{2+}\right\} /\left\{\mathrm{Ca}^{2+}\right\}_{\text {magnesite }}=10^{-8.1} / 10^{-8.48}=2.3988
\end{gathered}
$$




$$
\begin{gathered}
\left\{\mathrm{Mg}^{2+}\right\} \times\left\{\mathrm{Ca}^{2+}\right\} \times\left\{\mathrm{CO}_{3}^{2-}\right\}^{2}=10^{-17.12} \\
\left\{\mathrm{Ca}^{2+}\right\} \times\left\{\mathrm{CO}_{3}^{2-}\right\}=10^{-8.48} \\
\left\{\mathrm{Mg}^{2+}\right\} /\left\{\mathrm{Ca}^{2+}\right\}_{\text {dolomite }}=10^{-17.12} /\left(10^{-8.48}\right)^{2}=0.6918
\end{gathered}
$$

It is obvious that the cation exchange in the suspension of strontianite is minimal, but that in the suspensions of magnesite and dolomite is substantial. The differences between the initial and equilibrated $\mathrm{Ca}^{2+}$ concentrations cannot be regarded as the adsorption content of $\mathrm{Ca}^{2+}$ on these fillers. Instead, the total adsorption of $\mathrm{M}^{2+}$ on strontianite, magnesite and dolomite was calculated by determining the difference in the initial and equilibrated $\mathrm{M}^{2+}$ concentrations, where $\mathrm{M}$ represents the sum of $\mathrm{Ca}, \mathrm{Mg}$ and $\mathrm{Sr}$. The total adsorption content of $\mathrm{M}^{2+}$ on strontianite, magnesite and dolomite is slightly lower than that on calcite.
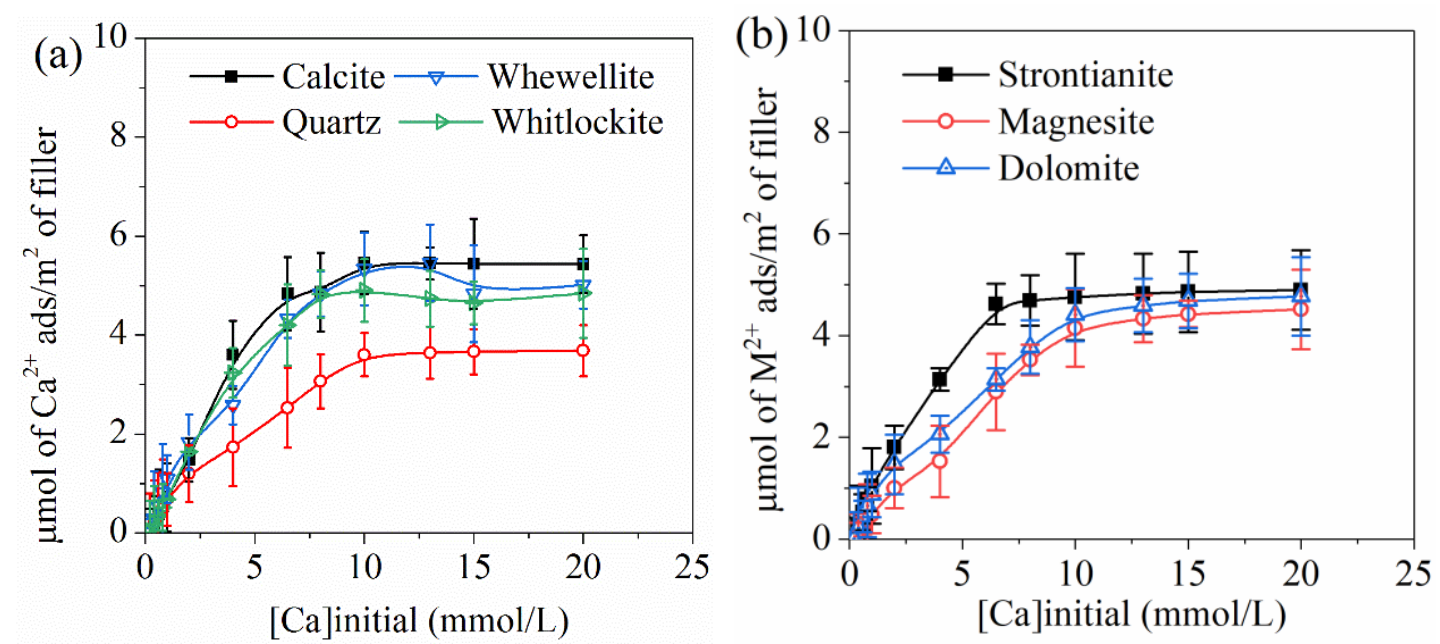

Fig. 3 Content of $\mathrm{Ca}^{2+}$ adsorbed on the unit surface area of fillers. (a) Adsorption of $\mathrm{Ca}^{2+}$ on the surface of fillers without ion exchange; (b) total adsorption of cations $\left(\mathrm{Ca}^{2+}, \mathrm{Sr}^{2+}\right.$ and $\left.\mathrm{Mg}^{2+}\right)$ on the surface of fillers with ion exchange.

\subsubsection{Zeta potential}

Fig. 4 shows the zeta potentials of various filler suspensions as a function of the initial calcium concentrations. As shown in Fig. 4, the $\mathrm{Ca}^{2+}$ concentration is approximately $2 \mathrm{mM}$ in the quartz suspension with zero zeta potential and is in good agreement with the isoelectric point (IEP) determined by Ouyang et al. [8, 12]. The zeta potentials of the calcite suspension at high $\mathrm{Ca}^{2+}$ concentrations are also consistent with the values reported by Ouyang, but the surface charge of calcite is positive even at the minimum $\mathrm{Ca}^{2+}$ concentration of $0.2 \mathrm{mM}$, illustrating that the IEP of the calcite suspension is less than $0.2 \mathrm{mM}$, which is only half of the value determined by Ouyang et al. 
$[8,12]$. The IEP of the calcite suspension has also been researched by Huang et al. [30] and Foxall et al. [36], and the value of the IEP is approximately $0.043 \mathrm{mM}$. The zeta-potential results of Pourchet et al. [31] also show that the surface charge of calcite is positive at the minimum $\mathrm{Ca}^{2+}$ concentration of approximately $0.2 \mathrm{mM}$. In fact, the surface charges of all ionic compounds are positive even at the minimum $\mathrm{Ca}^{2+}$ concentration in this study. The strong acid-base interaction leads to strong adsorption of $\mathrm{Ca}^{2+}$ on ionic compounds, while the relatively weak electrostatic interaction results in the high mobility of adsorbed $\mathrm{Ca}^{2+}$ on covalent compounds (quartz). In addition, the zeta potentials of the calcite and strontianite suspensions are higher than those of other ionic compound suspensions, illustrating the relatively higher affinity of $\mathrm{Ca}^{2+}$ for adsorption on calcite and strontianite, which is consistent with the adsorption experiment results in section 3.1.1.

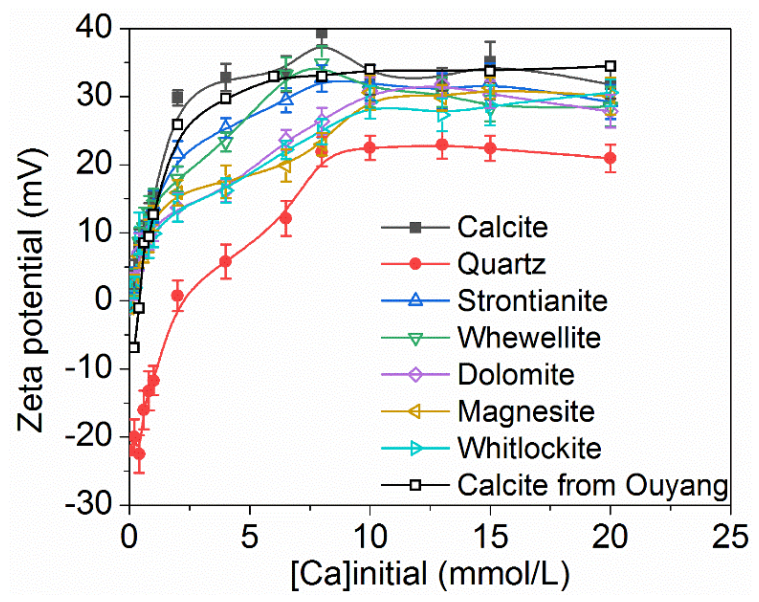

Fig. 4 Zeta potentials of the filler suspensions as a function of the initial calcium concentrations. Hollow box data are the zeta potentials of calcite suspensions adopted from Ouyang et al. $[8,12]$

\subsection{Morphology and structure of synthetic $\mathrm{C}-\mathrm{S}-\mathrm{H}$}

It has been reported that the morphology of C-S-H on calcite is different from that on quartz sand: an orderly arrangement of C-S-H was found on the surface of calcite while that on quartz was disorganized [7, 8]. However, the structure of the C-S-H that precipitated on the surface of fillers with various chemical charateristics has rarely been reported. Moreover, the dominant mechanism of the filler effect on the morphology of C-S-H has seldom been investigated. In this section, the morphology and structure of synthetic C-S-H on different fillers were observed.

\subsubsection{SEM}

The morphology of synthetic C-S-H was observed by SEM, and the results are presented in Fig. 
5. As shown in Fig. 5a, the pure C-S-H that precipitated in solution showed a flocculent morphology with particle sizes from $10 \mu \mathrm{m}$ to $100 \mu \mathrm{m}$ and presented an irregular distribution. Conversely, an ordered honeycomb-like pattern of synthetic C-S-H was found on the surface of calcite (Fig. 5b), which was also observed in cement-calcite blended systems [7, 8, 10, 12, 15]. Interestingly, it was found in the sparse area (marked as red circle) that the synthetic C-S-H grew along the lattice direction. Bentz et al. [10] also reported that the initially precipitated C-S-H pattern was consistent with the distribution of $\mathrm{Ca}$ and $\mathrm{O}$ atoms on calcite cleavage surfaces, as observed by Rode et al. [37]. Most interestingly, an ordered honeycomb-like pattern of synthetic C-S-H was also found on the surface of strontianite (Fig. 5c). This suggests that not the intrinsic $\mathrm{Ca}$ atoms but the $\mathrm{CO}_{3}{ }^{2-}$ exposed on the surface due to the slight dissolution of fillers is more likely to be the cause of the regular arrangement of CSH. However, a quite irregular leaf-like morphology of synthetic C-S-H was found on the surface of magnesite (Fig. 5d), which is caused by the conflict between the precipitation of C-S-H and the phase equilibrium of the carbonate minerals. As shown in Fig. 5d, some calcite crystals (marked with red circles) were found in the magnesite and C-S-H systems. The ICP experimental results also presented the rapid transformation from magnesite with a relatively higher solubility to calcite with lower solubility. This means that magnesite cannot provide a 'template surface' with stable physicochemical properties during the nucleation and growth of synthetic C-S-H. Thus, the initial CS-H nuclei randomly formed on the surface of magnesite and then grew rapidly in this arrangement. As analysed in section 3.1.1 (Eqs. 5 and 6), the cation exchange in the suspension of dolomite is weaker than that in the suspension of magnesite, and thus, the influence of the phase equilibrium of the carbonate minerals on the precipitation of $\mathrm{CSH}$ is less, resulting in a relatively ordered leaf-like morphology of C-S-H on the surface of dolomite (Fig. 5e). However, compared to those on other ionic compound fillers, the arrangement of C-S-H on dolomite is apparently irregular.

Similar to calcite and strontianite, whewellite and whitlockite are also ionic compounds; thus, the ordered honeycomb-like morphology of synthetic C-S-H is expected to be found on the surface of these fillers. However, the C-S-H on whewellite showed a leaf-like pattern (Fig. 5f). Interestingly, the leaf-like C-S-H is perpendicular to the surface of whewellite (marked as red circle in Fig. 5f), which is quite different from the irregularly distributed leaf-like morphology on dolomite. Both leaflike and honeycomb-like C-S-H were found on the surface of whitlockite, but the arrangements of C- 
$\mathrm{S}-\mathrm{H}$ are not as ordered as those on calcite and strontianite. Most interestingly, the synthetic C-S-H on the surface of quartz presented a parallel leaf-like pattern. This means that the growth orientations of synthetic C-S-H vary on different types of fillers: preferred vertical growth on the surface of ionic compounds and parallel growth on the surface of covalent compounds.
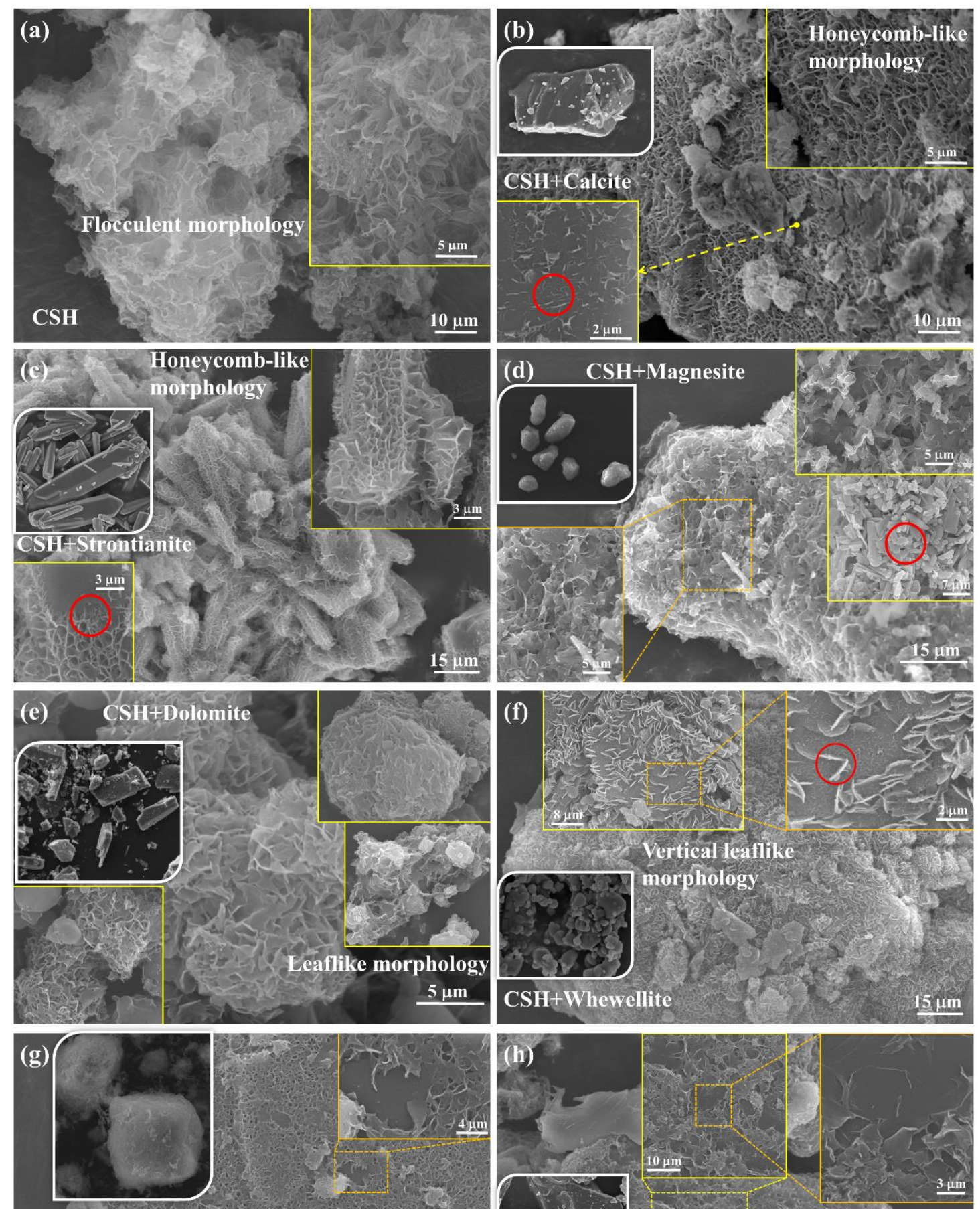

CSH+Whitlockite
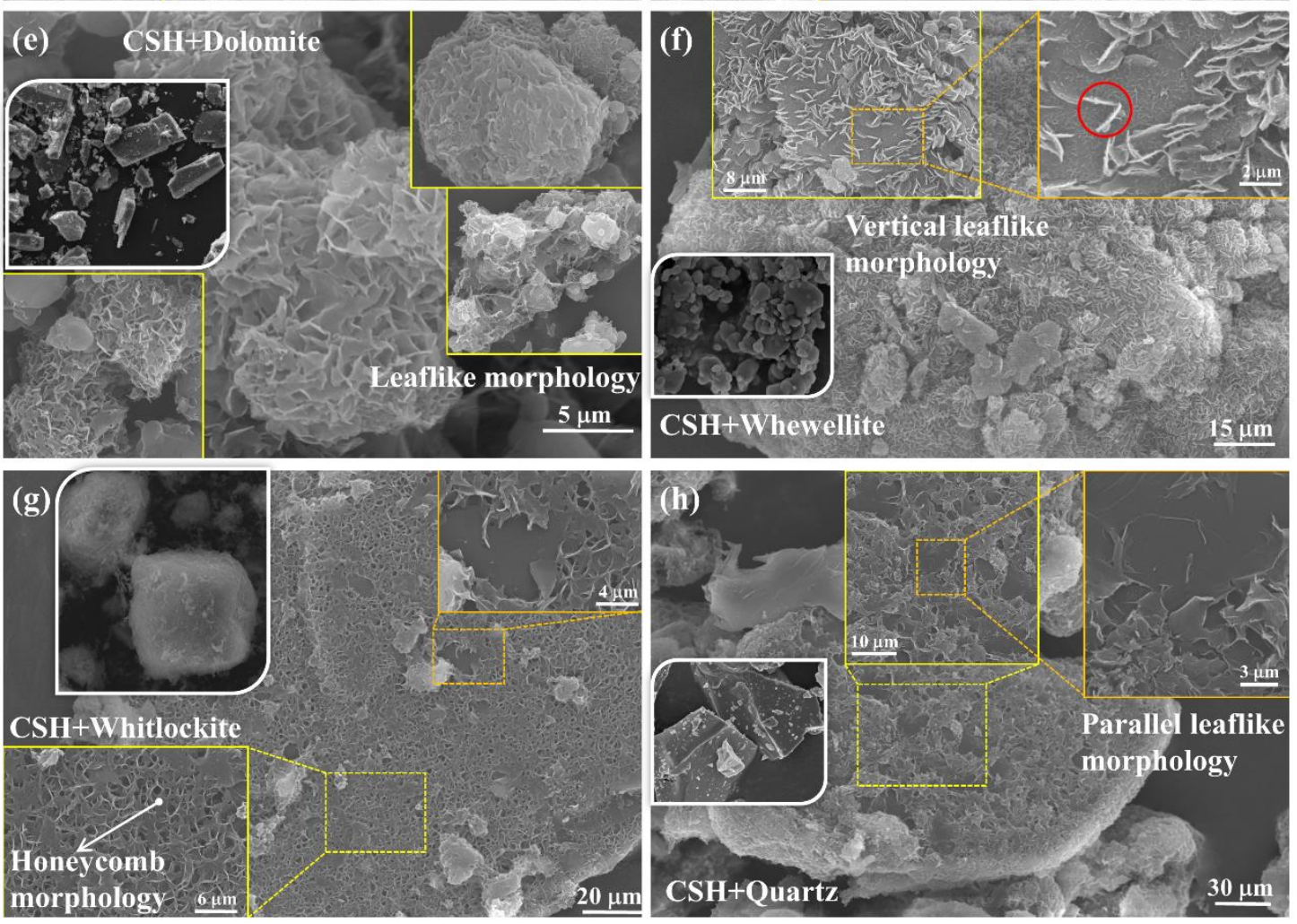
Fig. 5 SEM morphology of synthetic C-S-H on fillers. (a) Pure C-S-H, irregular flocculent morphology; (b) C-S-H on calcite, ordered honeycomb-like morphology; (c) C-S-H on strontianite, ordered honeycomb-like morphology; (d) C-S-H on magnesite, irregular leaf-like morphology; (e) C-S-H on dolomite, irregular leaf-

like morphology; (f) C-S-H on whewellite, vertical leaf-like morphology; (g) C-S-H on whitlockite, combined leaf-like and honeycomb-like morphology; (h) C-S-H on quartz, parallel leaf-like morphology. The small figures in white boxes in $b \sim g$ are the morphology of the raw fillers.

\subsubsection{TEM}
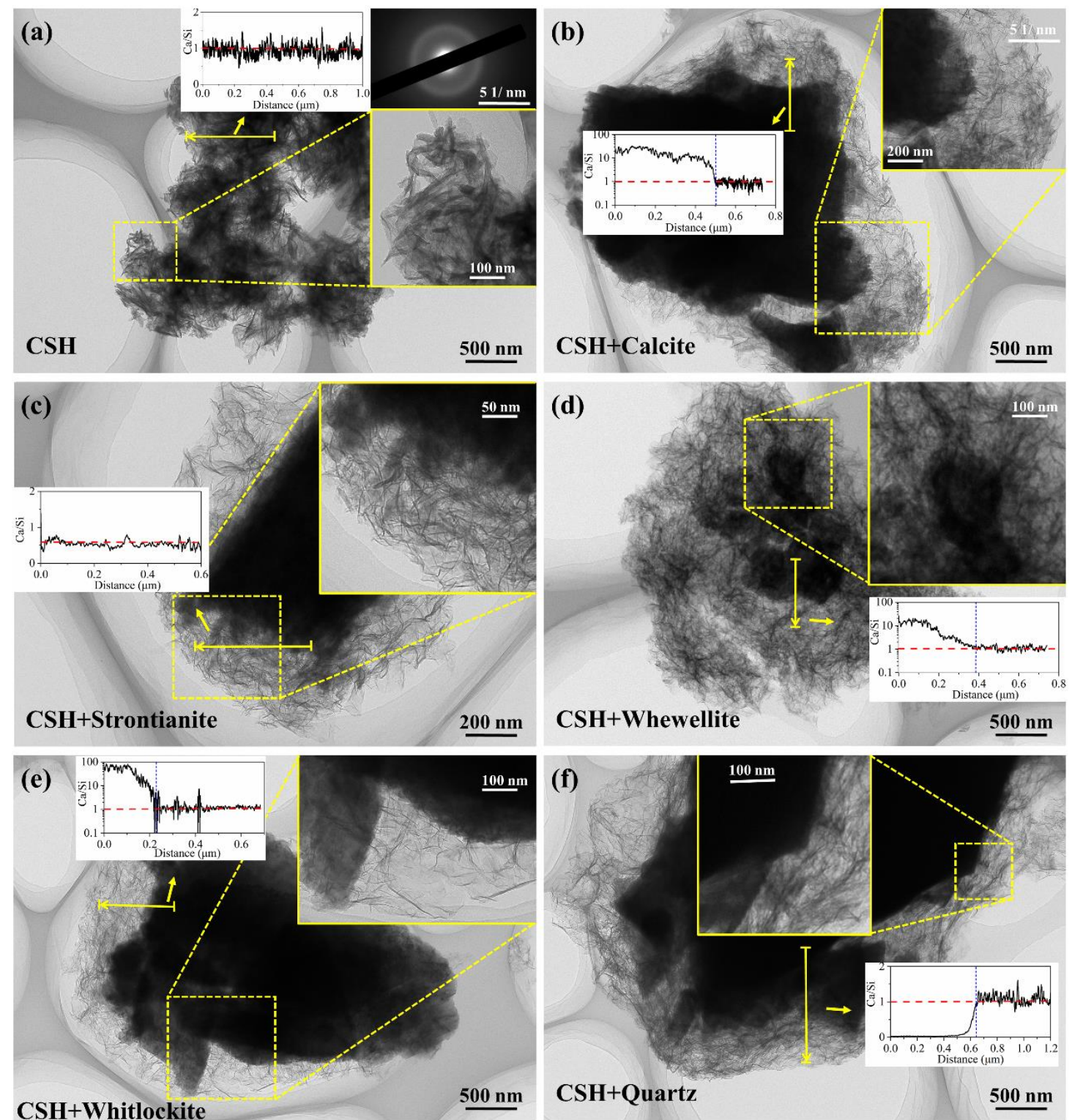

Fig. 6 TEM morphology of synthetic C-S-H on fillers. (a) Pure C-S-H; (b) C-S-H on calcite; (c) C-S-H on strontianite; (d) C-S-H on whewellite; (e) C-S-H on whitlockite; (f) C-S-H on quartz. The $\mathrm{Ca} / \mathrm{Si}$ ratio of C-S$\mathrm{H}$ on strontianite is approximately 0.7 , while those of the other C-S-H are approximately 1.0. (what are the 
insets?)

The structures of synthetic C-S-H on various kinds of fillers were also observed by TEM equipped with EDS, and the results are presented in Fig. 6. It should be noted that the TEM structures of C-S-H on magnesite and dolomite have not been observed since the precipitation of C-S-H is apparently affected by cation exchange in the suspensions of magnesite and dolomite. As shown in Fig. 6a, a foil-like synthetic C-S-H was found, and the diffraction pattern showed that the synthetic $\mathrm{C}-\mathrm{S}-\mathrm{H}$ is amorphous. Foil-like synthetic C-S-H was also found on the surface of fillers, illustrating that although inert fillers with different physicochemical properties can obviously influence the SEM morphology of C-S-H, they rarely affect the TEM structure of C-S-H.

The element composition of synthetic C-S-H was determined by $1 \mu \mathrm{m}$ line scanning with EDS. The $\mathrm{Ca} / \mathrm{Si}$ ratio of C-S-H was calculated, and the result in Fig. 6 a shows that the $\mathrm{Ca} / \mathrm{Si}$ ratio of C-S$\mathrm{H}$ is approximately 1.0 , which is consistent with the element proportions in solutions $\mathrm{A}$ and $\mathrm{B}$ during the synthesis process. The elemental compositions of C-S-H on the surface of the fillers are similar to those of C-S-H in solution, except for C-S-H on strontianite, which has a Ca/Si ratio of only 0.7. The decrease in the $\mathrm{Ca} / \mathrm{Si}$ ratio is likely caused by the cation exchange between $\mathrm{Ca}$ and $\mathrm{Sr}$, which results in a slight decrease in the Ca concentration in solution. Interestingly, the SEM morphology and TEM structure of C-S-H on calcite are similar to those of C-S-H on strontianite, although there is a significant difference between the $\mathrm{Ca} / \mathrm{Si}$ ratios of $\mathrm{C}-\mathrm{S}-\mathrm{H}$ on the surface of these two fillers. This means that the variation in the $\mathrm{Ca} / \mathrm{Si}$ ratio from 0.7 to 1.0 has little influence on the structure and morphology of synthetic C-S-H. Rodriguez et al. [38] reported that a foil-like C-S-H was obtained at $\mathrm{Ca} / \mathrm{Si}$ ratios from 0.7 to 1.5 , and fibrillar $\mathrm{C}-\mathrm{S}-\mathrm{H}$ was obtained at a high $\mathrm{Ca} / \mathrm{Si}$ ratio $(>1.5)$ via a silicalime reaction. The transformation of the morphology of synthetic C-S-H from foil to fibrils with increasing $\mathrm{Ca} / \mathrm{Si}$ ratio has been reported by many studies [39, 40]. The TEM structure of C-S-H on quartz is similar to that on the surface of ionic compounds, illustrating that the type of chemical bond in the fillers only affects the SEM morphology but not the TEM structure of synthetic C-S-H.

\subsection{Precipitation kinetics of synthetic $C-S-H$}

The precipitation kinetics of synthetic C-S-H were monitored by the electrical conductivity of the solution, and the results are presented in Fig. 7. Fig. 7a shows the electrical conductivity of the solution without fillers (red line) and its differential curve (black line). The electrical conductivity 
increases rapidly within the initial 10 min with the addition of solutions A and B. At approximately $10 \mathrm{~min}$, a platform was found on the electrical conductivity curve, and a valley appeared on the differential electrical conductivity curve, illustrating rapid consumption of the ions in solution that retards the growth of the electrical conductivity in solution. The appearance of the platform and the valley represents the start of the precipitation of $\mathrm{C}-\mathrm{S}-\mathrm{H}$. According to the classical nucleation theory $[41,42]$, the precipitation of $\mathrm{C}-\mathrm{S}-\mathrm{H}$ requires a certain oversaturation degree to overcome the nucleation barrier, and once enough stable nuclei are produced, rapid growth of C-S-H on these nuclei will consume a massive number of ions, resulting in the decrease in the electrical conductivity growth rate of the solution.
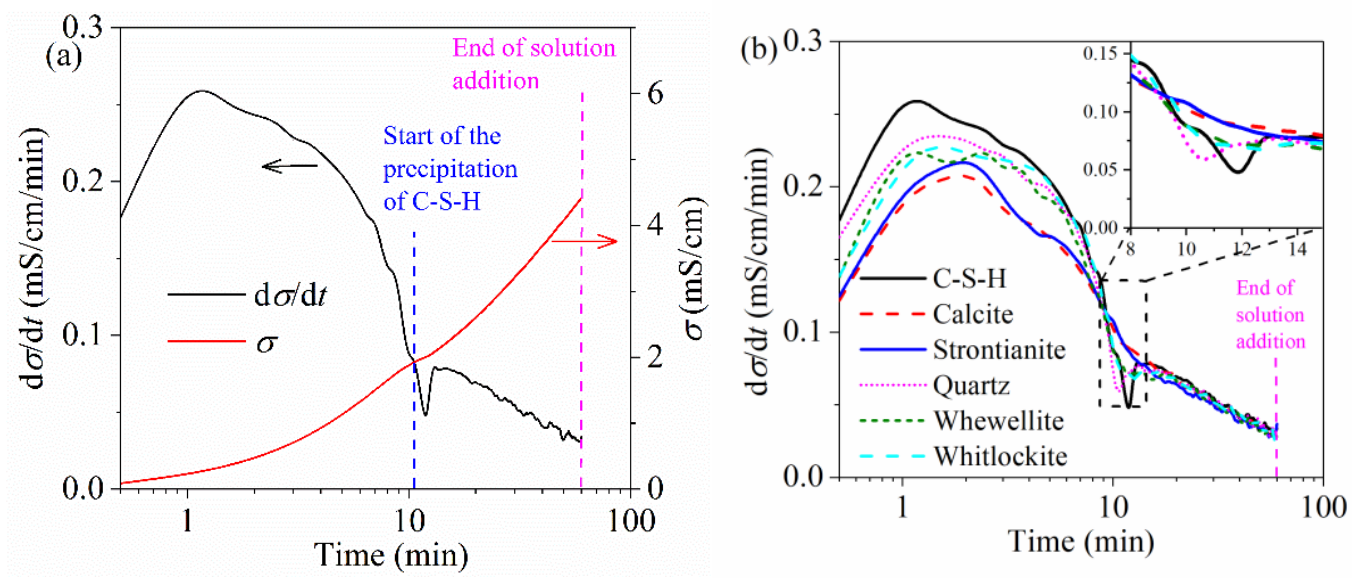

Fig. 7 The electrical conductivity of the solution. (a) The electrical conductivity of the solution without fillers (red line) and its differential curve (black line); (b) The differential electrical conductivities of solutions with or without fillers.

Fig. $7 \mathrm{~b}$ shows the differential electrical conductivities of the solution with or without filler. For the initial $10 \mathrm{~min}$, the growth rates of the electrical conductivities of the solutions containing fillers were lower than that of the pure solution, which is believed to be caused by the adsorption of ions on the fillers, as discussed in section 3.1. In fact, the growth rate of the suspension electrical conductivity was inversely proportional to the $\mathrm{Ca}^{2+}$ adsorption capacity of the filler. Similar to the case of the pure solution, a valley was found on the differential electrical conductivity curve of the quartz suspension, illustrating rapid precipitation of C-S-H. However, the valley occurred earlier and was smaller with the addition of quartz in solution. Additionally, the valleys in the differential electrical conductivity curves of the whewellite and whitlockite suspensions were inconspicuous. Most interestingly, no 
significant transition points were found on the differential electrical conductivity curves of the calcite and strontianite suspensions. This demonstrates that the precipitation of C-S-H did not occur suddenly in the filler suspension with the strong adsorption of calcium ions.
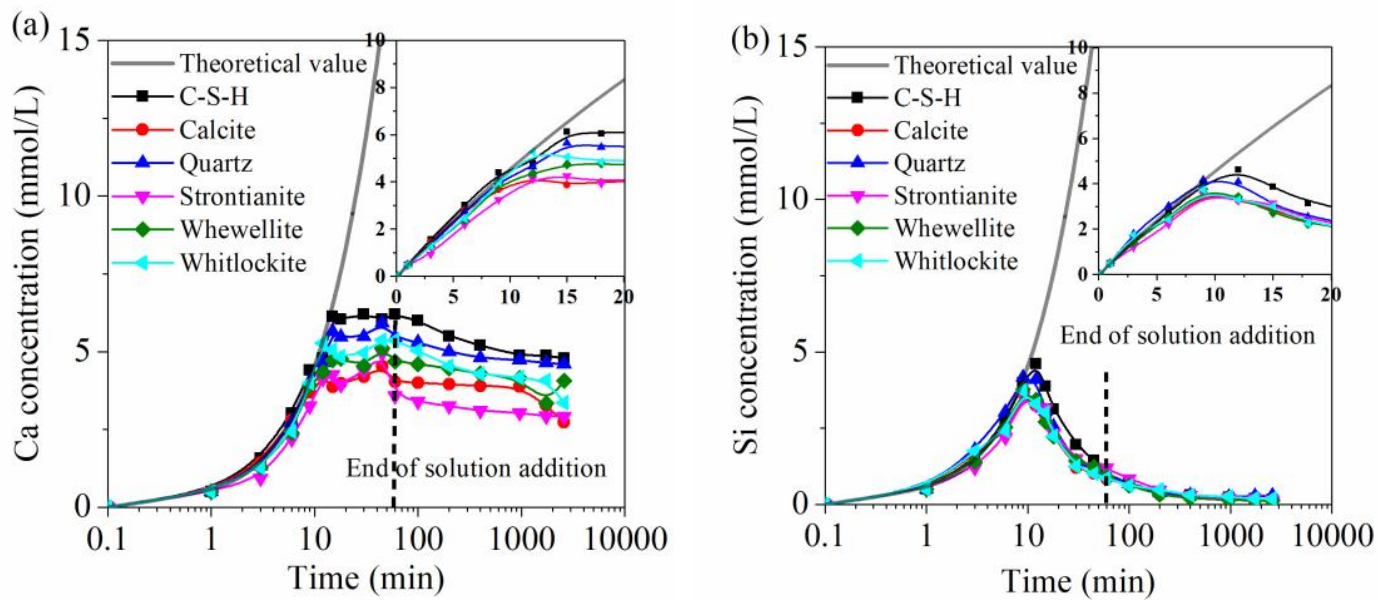

Fig. 8 Ion concentrations of the solutions. (a) Ca concentration decreases slowly after the precipitation of C$\mathrm{S}-\mathrm{H}$; (b) Si concentration decreases rapidly after the precipitation of C-S-H.

The ion concentrations were also measured to characterize the precipitation kinetics of C-S-H, and the results are presented in Fig. 8. The measured ion concentrations of the pure solution coincided exactly with the theoretical curve within the initial $10 \mathrm{~min}$, while those of the filler suspensions were slightly smaller than the theoretical value due to the adsorption behaviour of ions on fillers. This result is consistent with the electrical conductivity result. After approximately $10 \mathrm{~min}$, the Ca concentration decreased gradually, while the Si concentration decreased rapidly. The transition points on the ion concentration curves represent the start of the precipitation of C-S-H. As expected, the transition point appears earlier, and the ion concentrations at the transition points are lower in the filler suspensions with higher adsorption capacities for $\mathrm{Ca}^{2+}$.

Myers et al. [43] investigated the thermodynamic data of C-A-S-H gels in Portland cementbased materials. In this study, C-S-H_T5C [43] was selected to represent the synthetic C-S-H product, and its thermodynamic data are provided in Table 2 . The saturation index $\left(S I, S I=\ln \left(I A P / K_{s p}\right)\right)$ was calculated via a thermodynamic program PHREEQC, where $I A P$ and $K_{s p}$ are the ion activity product and solubility product, respectively. The calculated SI is presented in Fig. 9. Similar to the trend of the ion concentration, the saturation index also increased rapidly with the addition of solutions A and 
$\mathrm{B}$ and reached a maximum value at approximately $10 \mathrm{~min}$, followed by a gradual decline to zero. The transition point also represents the start of the precipitation of C-S-H. As indicated in Fig. 9, the precipitation of C-S-H occurred earlier, and the critical oversaturation degrees were lower in the filler suspensions with higher adsorption capacity for $\mathrm{Ca}^{2+}$, illustrating a lower nucleation barrier in these systems.

Table 2 Thermodynamic data of $\mathrm{CSH}$

\begin{tabular}{clccc}
\hline Phase & Reaction & $\log K_{s p}$ & $\triangle_{r} H^{0}$ & Ref. \\
\hline \multirow{2}{*}{ CSH_T5C } & $(\mathrm{CaO})_{1.25}\left(\mathrm{SiO}_{2}\right)_{1.25}: 2.5 \mathrm{H}_{2} \mathrm{O}+2.5 \mathrm{H}^{+} \leftrightarrow$ & & & \\
& $1.25 \mathrm{Ca}^{2+}+1.25 \mathrm{H}_{4} \mathrm{SiO}_{4}+1.25 \mathrm{H}_{2} \mathrm{O}$ & 18.74 & -83.46 & {$[43]$} \\
\hline
\end{tabular}

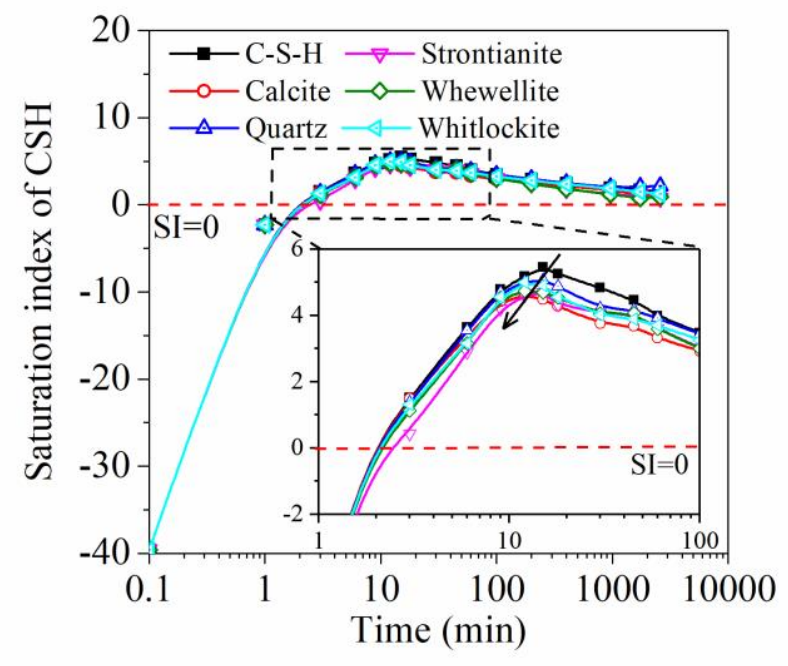

Fig. 9 Saturation index of C-S-H $\left(\mathrm{CSH}_{-} \mathrm{T} 5 \mathrm{C}, \mathrm{Ca} / \mathrm{Si}=1.0\right)$ in different systems.

According to the classical nucleation theory, the frequency of nucleation increases with the saturation index $[41,42,44]$ :

Frequency of nucleation:

$$
J=J_{0} \exp \left(-\frac{\Delta G^{*}}{k T}\right)
$$

For homogeneous nucleation in solution:

$$
\Delta G^{*}=\frac{f \Omega^{2} \gamma^{3}}{(k T \cdot S I)^{2}}
$$

$$
\text { For heterogeneous nucleation on fillers: } \quad \Delta G_{\text {het }}^{*}=\Delta G^{*}\left(\frac{1}{2}-\frac{3}{4} \cos \alpha+\frac{1}{4} \cos ^{3} \alpha\right)
$$

where the nucleation barrier $\triangle G^{*}$ is related to the interfacial crystal solution energy $\gamma$, the volume of the C-S-H molecule $\Omega$ and the saturation index SI. For heterogeneous nucleation on fillers, the nucleation barrier $\Delta G_{\text {het }}^{*}$ should be modified via the wetting angle $\alpha$. As shown from Eqs. 7 9, the nucleation barrier decreases with the addition of fillers due to the transition from homogeneous to 
heterogeneous nucleation. Moreover, the high affinity of $\mathrm{Ca}^{2+}$ for adsorption on fillers is supposed to decrease the wetting angle between C-S-H and the filler, thus further lowering the nucleation barrier. Especially for calcite and strontianite, the active surface sites $\left(\mathrm{CO}_{3}^{2-}\right)$ exposed due to slight dissolution could substitute with the $\mathrm{OH}^{-}$in C-S-H $[13,14]$, which is supposed to increase the compatibility and decrease the wetting angle between the filler and C-S-H gel. Therefore, the precipitation of C-S-H on fillers with a higher adsorption capacity for $\mathrm{Ca}^{2+}$ occurred earlier at a relatively lower oversaturation degree. It should be noted that whether $\mathrm{C}_{2} \mathrm{O}_{4}{ }^{2-}$ and $\mathrm{PO}_{4}{ }^{3-}$ have similar ion-exchange effects as $\mathrm{CO}_{3}{ }^{2-}$ remains for further experimental verification.

\subsection{Discussion}

The mechanisms for the effects of different fillers with various physicochemical properties on the nucleation of C-S-H are summarized in Fig. 10. First, the adsorption affinity of $\mathrm{Ca}^{2+}$ onto the surfaces of fillers remarkably affects the precipitation kinetics of the synthetic C-S-H [45]. The adsorption affinities of $\mathrm{Ca}^{2+}$ on calcite and strontianite are higher than those on any other inert fillers studied in this work (Figs. 10a and b), which is attributed to the strong acid-base interactions between $\mathrm{CO}_{3}{ }^{2-}$ (from calcite and strontianite) and $\mathrm{Ca}^{2+}$, resulting in a high content of adsorbed $\mathrm{Ca}^{2+}$, a low nucleation barrier and strong bond strength of the synthetic C-S-H. Although whewellite and whitlockite are also ionic compounds and the adsorption of $\mathrm{Ca}^{2+}$ on these fillers is also governed by acid-base interactions, the smaller lattice $\mathrm{Ca}^{2+}$ densities in these fillers lead to the low adsorption affinities of $\mathrm{Ca}^{2+}$ (Figs. 10c and d) and a relatively high nucleation barrier of synthetic C-S-H. In the cases of the quartz suspension, the adsorption of $\mathrm{Ca}^{2+}$ is governed by a weak electrostatic force, hence resulting in the lowest adsorption of $\mathrm{Ca}^{2+}$ (Fig. 10e) and the highest nucleation barrier for the synthetic C-S-H.

Second, the type of chemical bond in the fillers only affects the SEM morphology but not the TEM structure of synthetic C-S-H. The growth orientations of synthetic C-S-H vary on different types of fillers: preferred vertical growth on the surface of ionic compounds and parallel growth on the surface of covalent compounds (quartz in Fig. 10e). The structure of C-S-H is supposed to be a CaO sheet with silicate chains on both sides [46-49]. As shown in the right part of Fig. 10e (adapted from [48]), the two sets of paralleled dreierkette chains are not linked, and the extra interlayer space is occupied by an inner $\mathrm{Ca}^{2+}$ layer. The adsorption $\mathrm{Ca}^{2+}$ layer on the surface of quartz likely acts as 
the inner $\mathrm{Ca}^{2+}$ layer, and the silicate tetrahedral structure inside the quartz can be regarded as the silicate chains in the adjacent C-S-H structure. Thus, the C-S-H structure tends to grow parallel to the quartz surface and is linked with quartz via a loose adsorbed $\mathrm{Ca}^{2+}$ layer. This hypothesis is similar to the double layer interaction model reported by many research papers $[12,50]$.

Third, the lattice cleavage as well as the adsorption strength of $\mathrm{Ca}^{2+}$ determine the arrangement of synthetic C-S-H on fillers. The dislocations and defects are typically presented along the direction of the lattice cleavage of the crystal. The free energy of the crystal may be influenced by lattice defects [29], which makes the nucleation of synthetic C-S-H easier with a lower nucleation barrier in these positions. Additionally, both calcite and strontianite are crystals with obvious lattice cleavage (crystal structures shown in Figs. 10a and b). The solubility is also affected by the defects of the crystal [29], and the relatively high solubility at the defect results in more $\mathrm{CO}_{3}{ }^{2-}$ exposed on the surface, leading to the high affinity of $\mathrm{Ca}^{2+}$ for adsorption on these areas. The lattice cleavages of whewellite and whitlockite are not as regular as those of calcite and strontianite; thus, the guiding function of the lattice cleavage on the arrangement of C-S-H is weak. In summary, the regular distribution of defects along the lattice cleavage contributes to the ordered pattern of C-S-H on ionic compounds.

In addition, the active surface sites $\left(\mathrm{CO}_{3}^{2-}\right)$ exposed due to the slight dissolution of calcite and strontianite could substitute the $\mathrm{OH}^{-}$in the C-S-H $[13,14]$ (marked in black circle in Fig. 10), which further increases the compatibility of $\mathrm{CSH}$ and fillers and induces the regular arrangement of CSH. It should be noted that there is no direct evidence that $\mathrm{C}_{2} \mathrm{O}_{4}{ }^{2-}$ and $\mathrm{PO}_{4}{ }^{3-}$ have similar ion-exchange effects as $\mathrm{CO}_{3}{ }^{2-}$. 

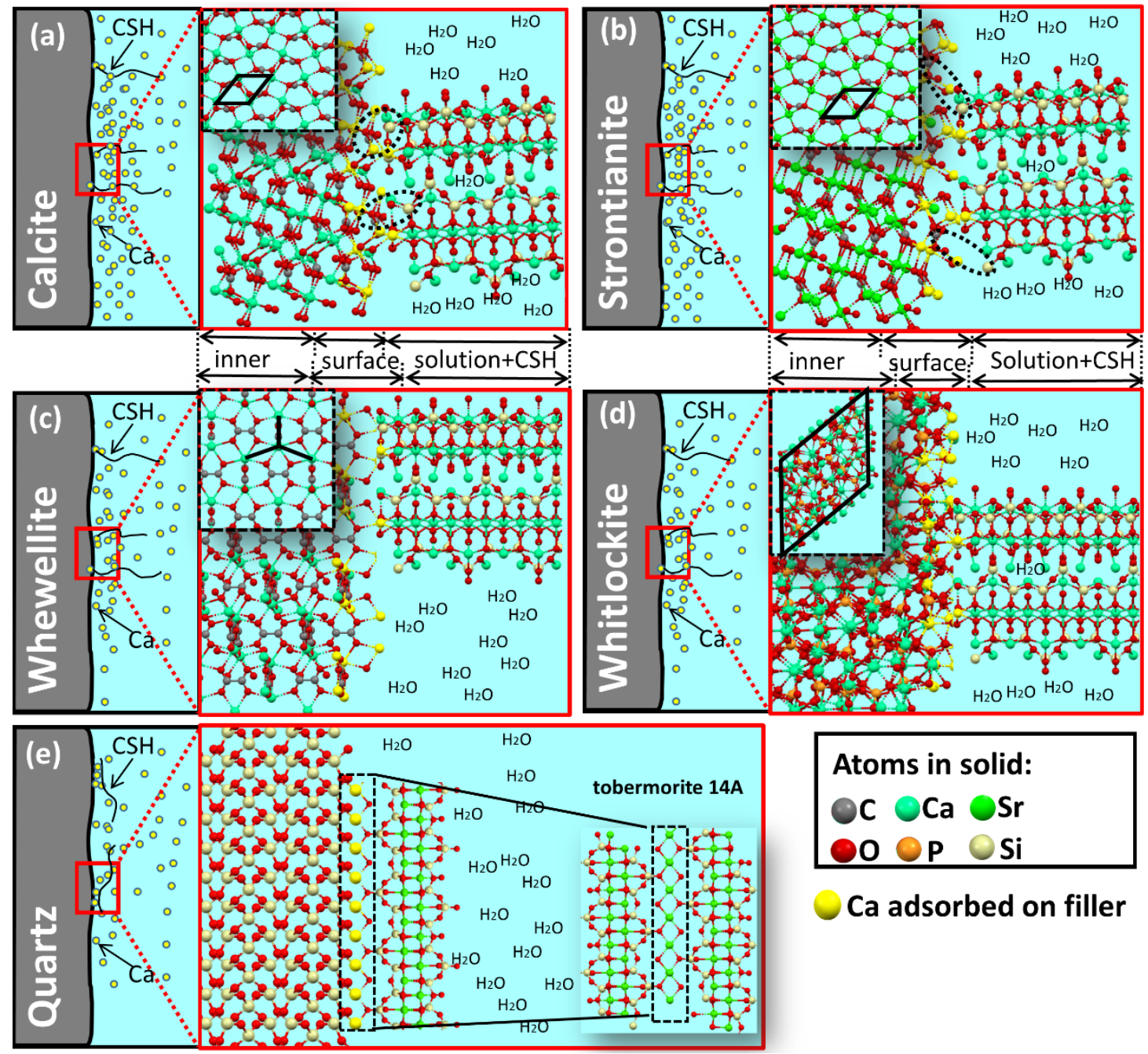

Ca adsorbed on filler

Fig. 10 Schematic diagram of the nucleation and growth of synthetic C-S-H on different fillers. (a) C-S-H on calcite; (b) C-S-H on strontianite; (c) C-S-H on whewellite; (d) C-S-H on whitlockite; (e) C-S-H on quartz.

\section{Conclusions}

This paper discusses the different 'filler effects' of several inert fillers with various physicochemical properties on the nucleation and growth of synthetic C-S-H. The affinities of $\mathrm{Ca}^{2+}$ for adsorption on different fillers were evaluated via ion concentration tests and zeta-potential tests. The structure and morphology of synthetic C-S-H in different systems were observed by TEM and SEM. The precipitation kinetics of C-S-H on the surface of different fillers were also characterized by monitoring the electrical conductivities and ion concentrations of the suspensions. Based on the experimental results in this study, the following conclusions can be drawn:

(1) A strong relationship between the affinity of $\mathrm{Ca}^{2+}$ for adsorption on fillers and the surface chemical properties is found due to the different driving forces of the adsorption process. A weak electrostatic force leads to the small affinity of $\mathrm{Ca}^{2+}$ for adsorption on inert covalent compounds (quartz), and a 
strong acid-base interaction results in a high affinity of $\mathrm{Ca}^{2+}$ for adsorption on inert ionic compounds. The abilities of ionic compounds to adsorb $\mathrm{Ca}^{2+}$ are related to both the strength of the acid-base interaction and the lattice $\mathrm{Ca}^{2+}$ density on the surface of fillers. The high affinity of $\mathrm{Ca}^{2+}$ for adsorption corresponds to a low nucleation barrier for synthetic C-S-H.

(2) The synthetic C-S-H precipitated on ionic compounds prefers to form along the normal direction, while that on quartz prefers to form along the tangential direction. The variation of the growth orientation of synthetic $\mathrm{C}-\mathrm{S}-\mathrm{H}$ on the quartz surface can be explained by the fact that the adsorbed $\mathrm{Ca}^{2+}$ layer acts as a loose $\mathrm{Ca}-\mathrm{O}$ sheet between the silicate tetrahedral chains in synthetic $\mathrm{C}-\mathrm{S}-\mathrm{H}$ and quartz.

(3) An extremely ordered honeycomb-like pattern of synthetic C-S-H is found on the surface of calcite and strontianite, while $\mathrm{C}-\mathrm{S}-\mathrm{H}$ on whewellite and whitlockite present less regular leaf-like or honeycomb-like patterns. The order of the synthetic C-S-H pattern is related to the lattice cleavage of the filler.

\section{Acknowledgments}

The authors would like to acknowledge the support of National Natural Science Foundation of China (Grant No. 51822807) and Tsinghua University’s Scientific Research Initiative Program.

\section{References}

1. Kumar A, Oey T, Kim S, et al (2013) Simple methods to estimate the influence of limestone fillers on reaction and property evolution in cementitious materials. Cem Concr Compos 42:2029. https://doi.org/10.1016/j.cemconcomp.2013.05.002

2. Poppe AM, De Schutter G (2005) Cement hydration in the presence of high filler contents. Cem Concr Res 35:2290-2299. https://doi.org/10.1016/j.cemconres.2005.03.008

3. Lawrence P, Cyr M, Ringot E (2005) Mineral admixtures in mortars effect of type, amount and fineness of fine constituents on compressive strength. Cem Concr Res 35:1092-1105. https://doi.org/10.1016/j.cemconres.2004.07.004

4. Lothenbach B, Le Saout G, Gallucci E, Scrivener K (2008) Influence of limestone on the hydration of Portland cements. Cem Concr Res 38:848-860. https://doi.org/10.1016/j.cemconres.2008.01.002

5. Bentz DP (2006) Modeling the influence of limestone filler on cement hydration using 
CEMHYD3D. Cem Concr 28:124-129. https://doi.org/10.1016/j.cemconcomp.2005.10.006

6. Mohamed AR, Elsalamawy M, Ragab M (2015) Modeling the influence of limestone addition on cement hydration. Alexandria Eng J 54:1-5. https://doi.org/10.1016/j.aej.2014.11.004

7. Berodier E, Scrivener K (2014) Understanding the filler effect on the nucleation and growth of C-S-H. J Am Ceram Soc 97:3764-3773. https://doi.org/10.1111/jace.13177

8. Ouyang X, Koleva DA, Ye G, van Breugel K (2017) Insights into the mechanisms of nucleation and growth of C-S-H on fillers. Mater Struct Constr 50:. https://doi.org/10.1617/s11527-017$1082-\mathrm{y}$

9. French CW, Mokhtarzadeh A (1993) High Strength Concrete: Effects of Materials, Curing and Test Procedures on Short-Term Compressive Strength. PCI J 38:76-87. https://doi.org/10.15554/pcij.05011993.76.87

10. Bentz DP, Ardani A, Barrett T, et al (2015) Multi-scale investigation of the performance of limestone in concrete. Constr Build https://doi.org/10.1016/j.conbuildmat.2014.10.042

11. Mehta P, Monteiro P (2006) Concrete: microstructure, properties, and materials. McGraw-Hill Education

12. Ouyang X, Koleva DA, Ye G, van Breugel K (2017) Understanding the adhesion mechanisms between C-S-H and fillers. Cem Concr Res 100:275-283. https://doi.org/10.1016/j.cemconres.2017.07.006

13. Oey T, Kumar A, Bullard JW, et al (2013) The filler effect: The influence of filler content and surface area on cementitious reaction rates. J Am Ceram Soc 96:1978-1990. https://doi.org/10.1111/jace.12264

14. Kumar A, Oey T, Falzone G, et al (2017) The filler effect: The influence of filler content and type on the hydration rate of tricalcium silicate. J Am Ceram Soc 100:3316-3328. https://doi.org/10.1111/jace.14859

15. Sato T, Diallo F (2010) Seeding effect of nano-CaCO3 on the hydration of tricalcium silicate. Transp Res Rec 61-67. https://doi.org/10.3141/2141-11

16. Plank J, Schönlein M, Kanchanason V (2018) Study on the early crystallization of calcium 
silicate hydrate $(\mathrm{C}-\mathrm{S}-\mathrm{H})$ in the presence of polycarboxylate superplasticizers. J Organomet Chem 869:227-232. https://doi.org/10.1016/j.jorganchem.2018.02.005

17. Wang F, Kong X, Wang D, Wang Q (2019) The effects of nano-C-S-H with different polymer stabilizers on early cement hydration. J Am Ceram Soc 1-14. https://doi.org/10.1111/jace.16425

18. Kanchanason V, Plank J (2017) Role of pH on the structure, composition and morphology of CS-H-PCE nanocomposites and their effect on early strength development of Portland cement. Cem Concr Res 102:90-98. https://doi.org/10.1016/j.cemconres.2017.09.002

19. Schönlein M, Plank J (2018) A TEM study on the very early crystallization of C-S-H in the presence of polycarboxylate superplasticizers: Transformation from initial C-S-H globules to nanofoils. Cem Concr Res 106:33-39. https://doi.org/10.1016/j.cemconres.2018.01.017

20. Nicoleau L (2010) New calcium silicate hydrate network. Transp Res Rec 42-51. https://doi.org/10.3141/2142-07

21. Nicoleau L, Gädt T, Chitu L, et al (2013) Oriented aggregation of calcium silicate hydrate platelets by the use of comb-like copolymers. Soft Matter 9:4864-4874. https://doi.org/10.1039/c3sm00022b

22. Li Y, Li H, Wang Z, Jin CC (2020) Effect and mechanism analysis of functionalized multiwalled carbon nanotubes ( MWCNTs ) on C-S-H gel. Cem Concr Res 128:105955. https://doi.org/10.1016/j.cemconres.2019.105955

23. Picker A, Nicoleau L, Burghard Z, et al (2017) Mesocrystalline calcium silicate hydrate: A bioinspired route toward elastic concrete materials. Sci Adv 3:. https://doi.org/10.1126/sciadv.1701216

24. Esteves LP (2011) Superabsorbent polymers: On their interaction with water and pore fluid. Cem Concr Compos 33:717-724. https://doi.org/10.1016/j.cemconcomp.2011.04.006

25. Sun J, Shi H, Qian B, et al (2017) Effects of synthetic C-S-H/PCE nanocomposites on early $\begin{array}{llll}\text { cement } & \text { hydration. } & \text { Constr }\end{array}$ https://doi.org/10.1016/j.conbuildmat.2017.02.075

26. Parkhurst DL, Appelo CAJ (2005) Description of Input and Examples for PHREEQC Inverse Geochemical Calculations Batch-Reaction, One-Dimensional Transport, and Version 3-A Computer Program for Speciation,. Cso 6-43A. https://doi.org/10.1016/0029-6554(94)90020-5 
27. Burgos-Cara A, Ruiz-Agudo E, Rodriguez-Navarro C (2017) Effectiveness of oxalic acid treatments for the protection of marble surfaces. Mater Des 115:82-92. https://doi.org/10.1016/j.matdes.2016.11.037

28. Popova A, Geoffroy G, Renou-Gonnord M-F, et al (2004) Interactions between Polymeric Dispersants and Calcium Silicate Hydrates. J Am Ceram Soc 83:2556-2560. https://doi.org/10.1111/j.1151-2916.2000.tb01590.x

29. Sposito G (1993) Chemistry of the solid-water interface. A Wiley-Interscience Publication, New York

30. Huang YC, Fowkes FM, Lloyd TB, Sanders ND (1991) Adsorption of Calcium Ions from Calcium Chloride Solutions onto Calcium Carbonate Particles. Langmuir 7:1742-1748. https://doi.org/10.1021/la00056a028

31. Pourchet S, Pochard I, Brunel F, Perrey D (2013) Chemistry of the calcite/water interface: Influence of sulfate ions and consequences in terms of cohesion forces. Cem Concr Res 52:2230. https://doi.org/10.1016/j.cemconres.2013.04.002

32. Pokrovsky OS, Mielczarski JA, Barres O, Schott J (2000) Surface speciation models of calcite and dolomite/ aqueous solution interfaces and their spectroscopic evaluation. Langmuir 16:2677-2688. https://doi.org/10.1021/la980905e

33. Papirer E (2000) Adsorption on Silicon Surfaces. CRC Press

34. Jang HM, Fuerstenau DW (1987) The Nature of Simple Monovalent Cation-Silica Interaction As Reflected in the Spin-Lattice Relaxation Time of 23 Na. Langmuir 3:1114-1118. https://doi.org/10.1021/la00078a041

35. Jönsson B, Nonat A, Labbez C, et al (2005) Controlling the cohesion of cement paste. Langmuir 21:9211-9221. https://doi.org/10.1021/la051048z

36. Foxall T, Peterson GC, Rendall HM, Smith AL (1979) Charge determination at calcium salt/aqueous solution interface. J Chem Soc Faraday Trans 1 Phys Chem Condens Phases 75:1034-1039. https://doi.org/10.1039/F19797501034

37. Rode S, Oyabu N, Kobayashi K, et al (2009) True atomic-resolution imaging of (1014) calcite in aqueous solution by frequency modulation atomic force microscopy. Langmuir 25:2850-2853. https://doi.org/10.1021/la803448v 
38. Rodriguez ET, Richardson IG, Black L, et al (2015) Composition, silicate anion structure and morphology of calcium silicate hydrates (C-S-H) synthesised by silica-lime reaction and by controlled hydration of tricalcium silicate (C3S). Adv Appl Ceram 114:362-371. https://doi.org/10.1179/1743676115Y.0000000038

39. Grudemo A (1954) Discussion following the paper by J.D. Bernal on 'The structure of cement hydration compounds.' In: Proc. 3rd Int.Symp. Chem. Cem. pp 247-253

40. KALOUSEK GL, PREBUS AF (1958) Crystal Chemistry of Hydrous Calcium Silicates: III, Morphology and Other Properties of Tobermorite and Related Phases. J Am Ceram Soc 41:124132

41. Pourchet S, Regnaud L, Perez JP, Nonat A (2009) Early C3A hydration in the presence of different kinds of calcium sulfate. Cem Concr Res 39:989-996. https://doi.org/10.1016/J.CEMCONRES.2009.07.019

42. Nielsen AE, Söhnel O (1971) Interfacial tensions electrolyte crystal-aqueous solution, from nucleation data. J Cryst Growth 11:233-242. https://doi.org/10.1016/0022-0248(71)90090-X

43. Myers RJ, Bernal SA, Provis JL (2014) A thermodynamic model for C-(N-)A-S-H gel: CNASHss. Derivation and validation. Cem Concr Res 66:27-47. https://doi.org/10.1016/j.cemconres.2014.07.005

44. Palberg T (1997) Colloidal crystallization dynamics. Curr Opin Colloid Interface Sci 2:607-614. https://doi.org/10.1016/S1359-0294(97)80053-2

45. Scrivener K, Ouzia A, Juilland P, Kunhi Mohamed A (2019) Advances in understanding cement hydration mechanisms. Cem Concr https://doi.org/10.1016/j.cemconres.2019.105823

46. Dharmawardhana CC, Misra A, Aryal S, et al (2013) Role of interatomic bonding in the mechanical anisotropy and interlayer cohesion of CSH crystals. Cem Concr Res 52:123-130. https://doi.org/10.1016/J.CEMCONRES.2013.05.009

47. Richardson IG (2008) The calcium silicate hydrates. Cem Concr Res 38:137-158. https://doi.org/10.1016/J.CEMCONRES.2007.11.005

48. Bonaccorsi E, Merlino S, Kampf AR (2005) The crystal structure of tobermorite $14 \AA$ (plombierite), a C-S-H phase. J Am Ceram Soc 88:505-512. https://doi.org/10.1111/j.1551- 
2916.2005.00116.x

49. Taylor HFW (1993) Nanostructure of C S H: Current status. Adv Cem Based Mater 1:38-46. https://doi.org/10.1016/1065-7355(93)90006-A

50. Pellenq RJM, Lequeux N, van Damme H (2008) Engineering the bonding scheme in C-S-H: The $\begin{array}{lllll}\text { iono-covalent } & \text { framework. } & \text { Cem } & \text { Concr } & \text { Res }\end{array}$ https://doi.org/10.1016/j.cemconres.2007.09.026 